\title{
The Jihadi Terrorism Awareness in the Italian Context
}

\section{Giunta S, Mannino G, La Fiura $\mathbf{G}^{*}$ and Bernardone A}

Department of Jurisprudence, Libera University Santa Silvia, Roma, Italy

*Corresponding author: La Fiura G. Department of Jurisprudence, Libera University Santa Silvia, Rome, Italy Tel: 7135006759; E-mail: giulianalafiura92@gmail.com Received date: May 18, 2018; Accepted date: June 25, 2018; Publication date: June 29, 2018

Copyright: $\odot 2018$ Giunta S, et al. This is an open-access article distributed under the terms of the Creative Commons Attribution License, which permits unrestricted use, distribution, and reproduction in any medium, provided the original author and source are credited.

\begin{abstract}
Islamic terrorism is an extremely complex, articulated and constantly evolving criminal phenomenon: born and rooted in Islamic culture, it has been expanding down to Western world and presents itself in different ways.
\end{abstract}

Terror is, as we shall see later, the primary object of terrorist groups: that is why we decided to conduct a pilot study with the aim of probing perception of the phenomenon on the part of the subjects.

In this regard, we conducted an innovative and unique study, analysing for the first time the results of 1493 questionnaires that have been administered to a sample of Italian university students, concerning the perception of this growing phenomenon.

the study has confirmed how the strategy of terror, whatever is its nature and its purposes, has a strong impact on lifestyles, on the formation of prejudices, on the general conception of the world; It shifts the coordinates and changes life perspectives.

The study is innovative in terms of perception of the terrorist phenomenon since it appears to be one of the first studies in this area focusing on the Italian context

Keywords: Terrorism; Psychology; Perception; Students; Empirical study

\section{Introduction}

Over time the term "Terrorism" has been used basically to indicate a particular strategy, implemented by the Government to subjugate the population, and subsequently, the term has started to indicate the systematic use of violence with political ends, put in place by illegal organizations to the detriment at the expense of state entities [1-5].

Even, "terrorism" could be defined as violence or threat of violence against non-combatants populations, with the aim of achieving a political, religious or even ideological objective through fear and intimidation [6].

As regards to the phenomenon with a religious (i.e. Islamic) matrix, the thorny problem concerning a Muslim is that he does not treat his belief as a marginal aspect or simply deprived of its life: Islamic faith influences, in fact, every action and act of a Muslim life [7].

Through a detailed analysis of the word Islam, we notice how the monotheistic religion founded by the Prophet Muhammad lays its foundation on the reliance of believers on the divine will. This abandoning of Muslims to divine will is one of the aspects that, according to Panella, discern Christians from Muslims: The formers have an alliance with God, the latters, instead, have "formal" relations with Allah to whom they must submit [8]. Islam is not only a religion, but also a political, social and cultural system that is strongly linked to ideology. In this respect, the Sharia (in literally Arabic means "sacred low") is the set of norms of religious derivation that regulate Muslims life. The whole Umma (i.e. The Muslim community) is governed only by God who is the Legislator and the Sharia, as a particular juridical system is imperative and immutable [9]. In other words, it is a theocratic system.

Actually, if we study Islamic culture in a slightly more careful way, it is quite clear that the jihadist cause rather than interpreting, distorts exasperates and exploits the Islamic values of which it speaks as spokesman.

It seems, at first sight, that terrorist movement takes motivations that can be traced back to religious explanations, but actually they embody political and economic motivations [5] so that the religious question becomes an alibi behind which the political nature of the clashes is hidden; after all, the same was also for Christians during the Crusades and even today, when the economic interests of Western countries are masked behind the facade of the crusade against the dictatorships and in favour of democracy.

Compared to the literature on terrorism, the psychosocial approach emphasizes how the phenomenon should not be conceptualized as a social or psychological syndrome, but as a method of socio-political influence [10]. In order to pursue these targets, terrorism, by instilling such fear, uses terror as an instrument [11-14] and its primary objective is not the physically injuring of the largest number of people, but that someone be a witness to such violence in order to spread and keep "alive" the climate of terror [15-22]. In this respect we tried to understand how the phenomenon in question is perceived in the Italian context, and specifically by university students. In other words, has the strategy of terror influenced their imagery, their fears, and their lifestyle? 


\section{The Research}

It is currently arduous to find empirical data concerning how the phenomenon is perceived, partly because it is difficult to evaluate individual reactions to a phenomenon in progress which interacts with other phenomena equally perceived as disturbing or even terrifying. In other words, the pressing migratory wave, the threat of an uncertain future, the thousand dangers of the "liquid society" (Bauman), all this is added to the perception of the terrorist risk, amplifying its scope and making it hard to make a specific assessment. In the awareness of this objective difficulty we have tried to carry out a pilot study by administering a semi-structured questionnaire, which have been created ad hoc to Italian university students, in order to probe their reactions and their emotions in relation to a phenomenon so dramatically present.

\section{Objectives of the Research}

The general objective of this work is to analyse how Italian university students perceive the terrorism phenomenon. There are four specific targets to be pursued:

- To identify how the subjects define the phenomenon, its causes and the motivations that push the suicide bombers to commit the attacks;

- Which may be, according to the sample, the future predictions on the progress of terrorism?

- Which are the reasons for the absence of attacks in Italy;

- Whether the phenomenon of terrorism affects the lifestyle of the participants.

- To this end, a semi-structured interview was created specifically for 1493 Italian university students.

\section{Subjects Involved}

The sample of the research, of simple random type [23-26], is made up of 1493 university students of which $73 \%$ are female; the age of the participants is between 18 and 25 years. $52 \%$ of them attend the course of study in in Northern Italy, $26 \%$ in Central Italy, and $22 \%$ in Southern Italy. $80 \%$ of the sample is in possession of a diploma, while $20 \%$ have a bachelor degree. $72 \%$ of the subjects in question do not have a job. Most of the students (about 77\%) attend courses in the Humanistic/Social Discipline field, $19 \%$ in the Scientific/Technological area, and the remaining $4 \%$ in the field of Health.

\section{Methodology and Tools}

The participants to the study voluntary decided to submit to the compilation of a semi-structured questionnaire, which was created ad hoc and composed of 39 questions. These latter was administered and disseminated through the social network Facebook and the instant messaging application WhatsApp.

Compared to these, the former are purely anamnestic, while the remaining part focuses on the following areas:weakness

- The area of the general classification of the phenomenon, with respect to which we try to detect how the sample defines the phenomenon and its causes;

- The area of future predictions on the trend of Islamist terrorism;
- The psychological area, focused on investigating whether and how the phenomenon has influenced the lifestyle and in the imagery of the sample.

For the purpose of evaluating closed questions, it was decided to represent the obtained data through graphs, reporting the emerged percentage frequencies.

As regards the open-ended questions, the obtained data were then analysed according to the Grounded Theory Method by Glaser and Strauss, which is used for the purposes of the analysis, with three coding phases:

- Open codification, in which labels are assigned to the phenomena, thus forming the concepts that are subsequently grouped into categories;

- Axial Coding, identifying the underlying relationships to the categories that have been identified in the previous phase;

- Selective encoding, defining the most generic, abstract and predominant categories, to which all the other categories are connected through relationships. It is a higher level of abstractness, which leads to the formulation of the theory [27].

Two independent judges [18] following a careful evaluation of the responses, have come to the common decision to build thematicconceptual maps:

- "General overview of the phenomenon"

- " "Prediction on the future trend of the phenomenon"

- "Reasons for the absence of terrorist attacks in Italy"

- "The influence of the phenomenon"

\section{Analysis of Data}

\section{Significant frequencies of the questionnaires}

From the carried out analysis, most of the Italian university students (about 73\%) believe that Italy will become a future target for terrorists; this thesis is supported by the idea that there are Jihadist cells not only within the Italian State, but also that the institutions do not protect citizens. According to what aforesaid it is easily deducible to understand how $50 \%$ of students believe that terrorism is one of the most serious problems for Italy.

Despite the aforementioned data, $71 \%$ of subjects are ready to state that they would be willing to choose as a destination for a possible trip a place that has been previously hit by an attack. Compared to how the perception of risk influences the mood of the subjects, $50 \%$ of them affirm that they did not feel safe in a crowded square.

Compared to the sample point of view of terrorists, it has been found that, according to $58 \%$ of the participants, the terrorists voluntarily undertake the path that will lead them to become part of the terrorist organizations. $67 \%$ believe that terrorists have psychological problems; nevertheless these mental disorders, according to $67 \%$ of the sample, are not due to traumatic events experienced in their childhood. Moreover, $61 \%$ of them believe that a possible cause for such disorders could be the condition of marginality in which they live.

Compared to the vision of the terrorist as impulsive, the answers provided by the students are not unique: $9.8 \%$ of the sample believes that they are extremely impulsive, while $26.4 \%$ imagines the terrorist as 
impulsive enough and 25\% absolutely does not consider the terrorist as impulsive.

On the other hand, the students mainly agree in affirming that terrorists are irrational subjects. This is also shown by the fact that the term "terrorism" is more associated with words like "madness" (53\%) and "fear" (46\%). Terrorists are also seen as quite intelligent subjects who can be driven by a desire of power. With respect to the religious question, $55 \%$ of the sample states that there is a relationship between Muslim religion and terrorism, and $37 \%$ believe that it is important enough to be a fervent practicing in order to be recruited by terrorist organizations. These statements, however, do not seem to involve in most of the students a less tolerant attitude towards Muslims.

Compared to how the sample imagines the terrorist, $39 \%$ represents him as a thin person, a characteristic associated, by $40 \%$ of the sample, to the "High" variable. As regards to this phenomenon, $46 \%$ of subjects affirm that they feel anger a lot, unlike the $3.1 \%$ who claims not to feel it at all.

\section{Thematic-conceptual maps}

In order to analyse the answers of the open-ended questions, we will present the thematic-conceptual maps built [18] that follows the Grounded Theory model by Glaser and Srauss. The maps have the function of explaining, clarifying and offering an immediate visualization of the most significant elements that have been obtained following the last phase of the Grounded Theory method: the phase of "selective coding", through which the most generic, abstract and predominant categories are defined and to which all other categories are linked through relationships. The thematic-conceptual maps we build are related to the following areas:

- "General overview of the phenomenon";

- "Prediction on the future trend of the phenomenon";

- "Reasons for the absence of terrorist attacks in Italy";

- "The influence of the phenomenon".

\section{Thematic-conceptual map "The general overview of the phenomenon"}

The sample in question defines terrorism in general as a "group of subjects" and then indicates three different peculiarities such as: the aim of instilling fear in subjects who are outside the group; the fact that they perform unjustified violence with the aim of intimidating; being religious fanatics. The participants also believe that the causes attributable to the phenomenon are mainly three: the attempt to acquire and exercise power over others (subjects/states) as a consequence of several years spent in poverty and social exclusion; the desire to revenge against Western countries that have colonized them by exploiting their resources; racial hate due to some to mere ignorance, and to others to religious indoctrination.

As regards the specific motivations of suicide bombers, the sample identifies two of them: one relates to the social exclusion faced by foreign individuals residing in a Western country, this marginalization seems to drive individuals to look for a group to belong to.

Another possible consequence of social exclusion is the development, by future suicide bombers, of mental illnesses (not identified by the sample) that would push them to enroll and later become themselves instruments/weapons for the attacks. Even religious fanaticism ("Fanaticism and extremism, the improper use of the concepts of a non-violent basic religion") is considered, along with the psychological disorders, as a possible motivation that would "encourage" the subjects to behave according to what is established by the religious extremists.

\section{Thematic-conceptual map "Predictions on the future trend of the phenomenon"}

Compared to the predictions made by the sample on the future trend of the terrorist phenomenon, it is noticed a lack of a univocal idea about its evolution. In fact, some of them are firmly convinced that this is an expanding phenomenon, while some others believe the phenomenon has reached a stalemate; lastly there is a group who believe that the phenomenon is coming to an end.

However, there are constants that characterize the three possible predictions (expansion, static, conclusion): both migration and military policies. The phenomenon could expand with the implementation of both permissive and repressive migration policies: with the former it would increase the number of foreign subjects that can be recruited as a consequence of the limited controls on immigration; with the latters, by not developing adequate integration policies, the vulnerability of the subjects would increase along with their ease of recruitment. Even the military policies against terrorism could cause the growth of the phenomenon, by triggering a movement of claim against West countries, this latter which would lead to a higher economic destabilization and therefore weakness/fragility, encouraging the actions of the terrorists themselves.

By contrast, the phenomenon could remain more or less static without undertake any type of military policy and increasing the efficiency of the Intelligence.

Some of the participants predict that the phenomenon will end either thanks to permissive migration policies which would determine a higher level of social integration and therefore higher difficulties in their recruitment; or by repressive migration policies, which would lead to limited access of foreigners in the country and the reduction of attacks; or also thanks to the military policies in order to eradicate the phenomenon directly from its root in the Middle East.

\section{Thematic-conceptual map "Reasons for the absence of terrorist attacks in Italy"}

There are three possible reasons identified by the sample for the absence of terrorist attacks in Italy: an efficient Intelligence; the consideration of Italy as a "bridge country" by terrorists; the little importance of Italy at international level.

Regarding the first reason, some participants to the study believe that the absence of terrorist attacks in Italy is due to the Intelligence, to its preventive measures on terrorism and the acquired experience during "the years of lead".

By contrast, others believe that terrorists consider it not useful to attack Italy, given that the territory is for them instrumental, used as a first stop from which then reaching the rest of Europe. This would be facilitated by the fact that, according to the sample, the country would carry out inadequate checks on immigrants; it would offer appropriate integration policies and geographically speaking it would be easy to reach.

Another reason for the absence of attacks in Italy is due to the little importance that Italy has at international level, given that it has not 
directly combatted an armed struggle against terrorism in Syria; it has not colonized those areas in the past, nor it implemented an aggressive foreign policy.

\section{Thematic-conceptual map "The Influence of the phenomenon"}

This map aims to illustrate how the phenomenon has influenced the participants in question. There are three areas that more than others have been conditioned by the phenomenon: that of dreams, that of fears and that of images. Regarding to dreams, there are frequent ones in which new or old attacks occur ("I dreamed twice in a row, in the same evening, myself inside the Bataclan, once living it as myself, the second time as a spirit that looked at myself"), which the subject assists or is involved in the first person. Sometimes even loved ones lose their lives ("There is not much to say. The terrorists exterminated with an attack all the people I love"). Students also present different fears, according to dreams: they are scared to lose their life or that of loved ones. Further fears are those concerning the outbreak of a world conflict or an existence marked by terror and unpredictability.

These fears have affected some people lifestyle, leading them to avoid, when possible, crowded public places, public transport (such as the subway and the plane); they have reduced the number of their travels and they watch with major suspect foreigners, especially if they are Muslims.

The subjects also describe several images of terrorist events relating to: death, violence, explosions, shootings and beheadings. Some of them relate to weapons/instruments used by terrorists in their attacks (bombs, machine guns, Kalashnikovs, trucks); others are linked to the images, spread by the media, of attacks that already occurred (that on the Twin Towers, Nice, Charlie Hebdo and Bataclan). They also include images such as the colour black, blood and the desert ("Middle-Eastern desert and armed men with covered face"; "To blood, to war, to death, to fear"; "To black colour, to death").

\section{Results}

In view of this analysis, it follows that the research objectives have been achieved overall. In this respect, the general aim of this study was to analyse how Italian university students perceive the phenomenon of terrorism. The first objective consisted on identifying how the subjects define the phenomenon and its causes, and the motivations that push the suicide bombers to commit the attacks: it has been seen that for some participants it is considered as a "group of subjects who have as a goal, the incitement of terror ". Others called them fanatics or violent subjects indiscriminately. But beyond the differences it was noted that almost all the subjects of the sample spoke of their fear of living in a state of terror and constant unpredictability. In other words, the "strategy of terror" seems to have influenced everyone, almost indiscriminately.

As we could see on a theoretical level, the phenomenon of terrorism is a form of psychological warfare [28] where terrorization is the immediate goal of these groups. Therefore, in some respects the terrorist event is, before being a physical attack, a psychosocial aggression: the physical dimension is secondary to the psychological effects induced in the community [29].

The characteristic of "madness" is often associated with terrorists. In this regard, some scientific contributions in this area $[28,30,31]$ show that terrorists are not attributed significant psychic dysfunctions, or rather, they are not given greater mental discomfort than those of other criminals. As for suicide bombers, however, studies have shown a certain degree of a case of mental instability [32]. However, associating the figure of the terrorist with that of the madman takes on a more relevant meaning, as it is well known that madness is associated with unpredictable actions, with a broken personality, with hallucination, with the impossibility of frame the insane subject in a reassuring rational scheme. Apparently it is of little use that many studies have not found important differences between criminal mentality and that of terrorist in terms of mental health. The subjects of the sample labelled terrorism as madness and have more than anything else talked about themselves and their attitude towards this phenomenon, the latter in all respects similar to that they adopt towards madness.

Regarding the second objective of the research, it investigates which may be future predictions on the progress of terrorism, according to the sample: it emerged that there is a dichotomy between what emerged from the percentage frequencies and what emerged, instead, from the thematic-conceptual maps.

Indeed, from the percentage frequencies it emerges that most of the students (73\%) say that Italy will become a future target for terrorists, while from the thematic-conceptual maps it emerges that most of them believe that it won't happen in their own city [33] came to the same conclusions, investigating the perception of the danger of terrorism by the Canadian population. It is defined as a bias of optimism, i.e. the subjects believe that negative events are less likely to happen to themselves than to others [34].

These results are similar to those achieved by [35] studying the perception of terrorist risk by Americans following the 9/11 attacks. The research show the fact that terrorism is perceived as one of the greatest problems in the country but, according to the optimism bias, the individual American citizens do not consider the eventuality of attacks in or around the areas they live in.

Focusing on the third specific objective of the research, it has been therefore analysed the answers concerning the reasons why, according to the sample, there would not have been terrorist attacks of Islamist origin in our country. Also in this case, it can be noticed the presence of some inconsistent elements with respect to other answers given by the sample above.

Indeed, the subjects (in high percentage) had previously stated to feel themselves unprotected by the State against possible attacks. However a part of the subjects states that the attacks would not have occurred in Italy thanks to the work of an efficient Intelligence that would be exploiting the experience gained in the so-called "years of lead". It is difficult to understand the causes of this incongruity, but we must think about the all-Italian attitude towards what is considered "State": it is possible that referring to the work of intelligence, the subjects mean more likely the work of the spearheads of our order services, while talking about "State" they refer more to politicians.

The fourth objective of the study aimed to determine how the phenomenon has influenced the participants, their dreams, their fears and their lifestyle. It emerged a further incongruity between percentage frequencies and thematic-conceptual maps: it deals with a change in their lifestyle. In fact, $71 \%$ of the subjects are ready to affirm that they would not exclude, as a possible destination for a trip, a country that has previously hit by an attack and that $50 \%$ stated that they did not feel safe in a crowded square. 
Page 5 of 6

Nevertheless, the maps show, in addition to their decreased attitude to travel (in general), how is also widespread the feeling of alert, danger and of suspicion towards foreign subjects. This could indicate that subjects are not fully aware of the influence of the phenomenon on their lifestyle.

It should, however, be emphasized that the typology of the closedended question and the open-ended question trigger different types of "psychological response". Faced with a question that requires only a yes or a no, in which No means to precisely admit that one's lifestyle has been changed by the climate of terror spread by the attacks, the subjects have the possibility to deny that their own world has undergone strong limitations. On the other hand, when the answer can be openly argued, it is easier for fears to appear: such dramatic events could have not failed to have deeply upset each of the subjects.

A reduction in the attitude to travel, and especially on the plane, is consistent with the results obtained by [36]. He noted how changed the attitude to travel on plane in students after the attack September $11^{\text {th }}$ attack.

Dreams, images and fears associated with the phenomenon are further relevant indicators: it is with respect to the dreamlike dimension and the imaginary that the phenomenon has left major effects. Images of death, fear and blood, are those that recur most.

Taking into account what aforesaid and comparing it with the results obtained from the research, we are able to affirm that the terrorist attack "has already struck" the Italian students, even if no terrorist attack has effectively occurred in our country.

Or even, some participants have changed certain aspects of their lifestyle (avoiding crowded squares, public transport, demonstrations, concerts, etc.), but also their attitudes and their ways of feeling, especially as regards their suspicions against foreigners, their general restlessness and the growing sense of danger for themselves and their family/ friends.

Obviously, living in a condition of terror and general instability, prejudices and stereotypes can easily be reinforced: it is a sort of "economy of feeling", generally very useful in case of danger in which it must decide who is a friend who is not.

It is natural if we analyze the real situation, it could be notice that among the subjects who enlist in the Islamic State (Isis) there are also individuals born and raised in the West and among these not only children of Muslims integrated in our countries but also boys and girls born of "typical" Western families.

It is obvious that the media pressure, based on what is news and what is more viscerally perceived, plays its role in this process of typing good and evil. Of course students, although they have more tools than the audience media, they are not able to escape the force of this pressure. In any case it must be kept in mind that this is a situation that arises from a "state of fear" and that this latter, by its nature, tends to suspend the critical abilities in favor of the immediate reactions.

Also interesting appears the analysis of the spontaneous association with the term "terrorism" done by the subjects. The most common associations concerned the color black, the terms "Muslim", "blood", "covered face", "desert".

Except for the term "black", which is actually associated in our imagery with something negative, obscure, disturbing (as well as connecting in this case to racial prejudices) the other terms are more specific: Muslim, covered face and desert identify all that we define in our imagination as Islamic or Arabic. The covered face has also a disturbing connotation: we may think of the heated debate that broke out as a consequence of the proposal to prohibit Muslims to cover their faces in public places. In West countries, uniformity is disturbing: the individual is such because he is different from others and the idea that individuals do not distinguish themselves from each other is repugnant to our concept of freedom. In this case, however, the veiled or covered face could also represent the fear in front of an enemy that could not easily be identified.

The study is innovative in terms of perception of the terrorist phenomenon since it appears to be one of the first studies in this area focusing on the Italian context, and therefore it also represent a possible basis for future new investigations.

\section{Conclusions}

Terrorism of Islamic origin appears to be a new form and declination of the terrorist phenomenon, which unlike many others does not only affect the local level but rather overcomes the borders of nations affecting the balance and the world scenarios. The jihadist message is strengthened by a series of aesthetic factors, purposely studied and built to breach the unconscious, pushing to embrace the ISIS cause.

What is being implemented by the terrorist group is a readjustment of the mythical image of the Caliphate to its own ideological needs, transforming this world into a place of refuge for true believers, into a land of redemption from which the Islamic State revolution will start; this latter would represent the "incarnation of dreams and fantasies" that are offered in these images. By taking over an originally western idea, the Caliphate exploits its astonishing exotic and seductive character in order to attract its foreign fighters.

Isis offers a cause for fighting and an opportunity to become protagonists of their lives and history.

The potential recruits are asked to abandon the world of origin, now corrupt and devoid of values, to reach a new land made of simple and clear values: the Islamic State, in which all members are brothers of the same community, fighting for the same ideal and wishing to sacrifice their lives to achieve the supreme goal. The ever more numerous followers coming from the western countries experience this journey to Syria, through Turkey as a real catharsis, as the beginning of a path of rebirth, which allows the "true" believer to redeem himself, to emancipate himself from corruption and ignorance. He makes his destiny fulfill itself, becoming a fighter and so finding his place in the world.

Above all, foreign fighters seem not to be interested in deepening the complexity of the Islamic religion, but rather they seek a cause for fighting with simple values, clear rules and a clear dichotomy between good and evil; they hope to realize themselves in this new utopia, the last one remained in the post-ideological era of globalization. As [30] states, one of the most powerful weapons of Isis is not the Koran, but the learned use of psychology.

As it has been analyzed, in the age of chaos characterized by the loss of traditional values, jihad and martyrdom assure the most reassuring future, mixed by promises of order and glory.

Therefore, they voluntary let themselves to be shaped by the radicalization process and despite being lucid, they chose between alternative behaviors, a choice that guarantees them a purpose in life, 
filling the empty left by the impossibility to the typical planning characterizing the modern age.

Having said that, the study conducted on the perception of university students of the terrorist phenomenon has confirmed how the strategy of terror, whatever is its nature and its purposes, has a strong impact on lifestyles, on the formation of prejudices, on the general conception of the world; It shifts the coordinates and changes life perspectives. In this sense, terrorism has doubtless marked a point in its favor, making the young people way of view the world much more frightened and fearful. In conclusion, it is certainly important to continue to investigate the phenomenon of terrorism not only to develop more awareness, but also to prevent the "indirect" but potentially devastating effects that the phenomenon produces on our society: first of all, fear that elicits irrational and potentially dangerous attitudes; then prejudiced and racist attitudes.

Widening the area of awareness of the phenomenon "terrorism" means going deeper and preventing less visible effects that in the long run will produce those "evils" that trigger the chain of actions and reactions: that feeds the terrorism itself.

\section{Ethical Approval}

All procedures performed in studies involving human participants were in accordance with the ethical standards of the institutional and/or national research committee and with the 1964 Helsinki declaration and its later amendments or comparable ethical standards.

This article does not contain any studies with animals performed by any of the authors.

\section{Informed Consent}

Informed consent was obtained from all individual participants included in the study.

\section{References}

1. Sorel JM (2003) Some questions about the definition of terrorism and the fight against its financing. EJIL, 14:365-378.

2. Lamberti C (2014) The tools to combat terrorism and cyber-terrorism in the European context. Journal of Criminology, Victimology and Security 8:138-161.

3. Laqueur W, Sandermann L (1978) History of Terrorism. Rizzoli. Milan, Italy

4. Schmid AP (2004) Frameworks for conceptualising terrorism. Terrorism and political violence 16: 197-221.

5. Napoleoni L (2014) ISIS, The State of Terror. Feltrinelli: Milano,Italy.

6. Post JM, Ali F, Henderson SW, Shanfield S, Victoroff J, Weine S (2009) The psychology of suicide terrorism. Psychiatry: Interpersonal and biological processes, 72: 13-31.

7. Lewis B (1995) Europe and Islam. Bari: Laterza, Rome,Italy.

8. Panella C (2009) It is not the same god, it is not the same man. Bible and Koran compared. Siena: Cantagalli publisher.

9. Papa M, Ascanio L (2014) Shari'a. The sacred law of Islam. Bologna: Il Mulino, Rome,Italy.

10. De la Corte Ibañez L, Kruglanski A, De Miguel J, Sabucedo JM, Díaz D (2007). Seven psychosocial principles to explain terrorism. Psicothema, 19: 366-374.

11. Schmid AP (1992) The response problem as a definition problem. Terrorism and Political Violence, 4: 7-13.
12. Mannino G, Giunta S, Buccafusca S, Cannizzaro G, Lo Verso G (2015) Communication Strategies In Cosa Nostra: An Empirical Research, World Futures: J New Paradigm Res 71: 1-20.

13. Mannino G, Giunta S (2015) Psychodynamics of the Mafia Phenomenon: Psychological-clinical research on environmental tapping and whitecollar crime, World Futures: J New Paradigm Res 71: 1-17.

14. Giunta S, Lo Verso G, Mannino G (2017) Betrayed dignity. A psychosocial study on the crime of white-collar workers, Milano: FrancoAngeli Publications, Italy.

15. Jenkins BM (1985) The future course of international terrorism. In Wilkinson PC, Stewart AM (Eds.). (1987). Contemporary research on terrorism. Aberdeen University Press.

16. Peirone L (2001) Extreme terrorism and its paradoxical psychological lessons. Trad. It. Extreme terrorism and its paradoxical psychological lessons. Paper submitted to Anima mundi. Globalization as a challenge.

17. Mannino G, Montefiori V, Faraci E, Pillitteri R, Iacolino C, et al. (2017a) Subjective perception of time: Research applied on Dynamic Psychology, World Futures: J New Paradigm Res 73: 1-18.

18. Mannino G, Giunta S, La Fiura G (2017b) Psychodynamics of the Sexual Assistance for Individuals with Disability G Sex Disabil 35: 1-12.

19. Taylor M, Horgan J (Eds.) (2000) The future of terrorism. London: Frank Cass publications, UK.

20. Taylor M, Horgan J (2006) A conceptual framework for addressing psychological processes in the development of the terrorist. Terrorism and Political Violence 18: 585-601.

21. Giunta S, Verso GL (2012) In the name of the Godfather. IJPE 4: 1-18.

22. Giunta S, Verso L, Mannino G (2016) The Mafia World: Between clinical practice and interventions in the polis. Editorial Company ARPAnet, Genova, ISSN 2037-5727

23. Corbetta P (1999) Methodology and techniques of social research. Bologna: Il Mulino.

24. Palumbo M, Garbarino E (2006) Social research: method and techniques. Milano: FrancoAngeli Publications, Italy.

25. Kazdin AE (2008) Research methods in clinical psychology. Bologna: Il Mulino.

26. Cimagalli F (2003) Evaluation and social research. Basic guidelines for social workers. Milano: Franco Angeli Publications, Italy.

27. Glaser BG, Strauss AL (2009) The discovery of Grounded Theory. Strategies for qualitative research. Rome: Armando Editore.

28. Horgan J (2015) Psychology of terrorism. Milano: Edra Masson. American Psychologist 72: 199-204.

29. Pezzullo L (2017) Psychosocial aspects of terrorism. Life in the times of terrorism. In Life in the days of terrorism Peirone L (2017).

30. De Rosa C (2016) In the mind of a jihadist: For a psychology of ISIS: Corriere della sera. Milano, Italy.

31. McCauley C (2012) Terrorism research and public policy.Routledge. Frank Cass publications, UK

32. Bhui K, James A, Wessely S (2016) Mental illness and terrorism. BMJ Publishing Group Limited.

33. Lemyre L, Turner MC, Lee JE, Krewski D (2006) Public perception of terrorism threats and related information sources in Canada: implications for the management of terrorism risks. J Risk Res 9: 755-774.

34. Weinstein ND (1980) Unrealistic optimism about future life events. J Pers Soc Psychol 39: 806-820.

35. Bloch-Elkon Y (2011) The polls-trends: Public perceptions and the threat of international terrorism after 9/11. Public Opin Q 75: 366-392.

36. Bergstrom RL, McCaul KD (2006) Perceived risk and worry: The effects of 9/11 on willingness to fly. Journal of Applied Social Psychology 34: 1846-1856. 